\title{
PLGA nanoparticle-mediated delivery of tumor antigenic peptides elicits effective immune responses
}

This article was published in the following Dove Press journal:

International Journal of Nanomedicine

14 March 2012

Number of times this article has been viewed

\author{
Wenxue $\mathrm{Ma}^{\prime}$ \\ Mingshui Chen' \\ Sharmeela Kaushal ${ }^{1,2}$ \\ Michele McElroy ${ }^{1,2}$ \\ Yu Zhang ${ }^{3}$ \\ Cengiz Ozkan ${ }^{3}$ \\ Michael Bouvet ${ }^{1,2}$ \\ Carol Kruse ${ }^{4}$ \\ Douglas Grotjahn ${ }^{5}$ \\ Thomas Ichim ${ }^{6}$ \\ Boris Minev 1,7,8 \\ 'Moores Cancer Center, University of \\ California San Diego, ${ }^{2}$ Department of \\ Surgery, University of California San \\ Diego, ${ }^{3}$ Laboratory of Biomaterials \\ and Nanotechnology, University of \\ California Riverside, ${ }^{4}$ UCLA Division \\ of Neurosurgery, Los Angeles, \\ ${ }^{5}$ Chemistry Department, San Diego \\ State University, San Diego, ${ }^{6}$ MediStem \\ Inc. San Diego, ${ }^{7}$ UCSD Division of \\ Neurosurgery, San Diego, ${ }^{8}$ Genelux \\ Corporation, San Diego, CA, USA
}

Correspondence: Wenxue Ma and Boris Minev

Moores Cancer Center, University of California San Diego, 3855 Health Sciences Drive, La Jolla, CA, 92093 USA Tel +l 8585349995

Fax + I 8585344994

Emailwma@ucsd.edu; bminev@ucsd.edu
Abstract: The peptide vaccine clinical trials encountered limited success because of difficulties associated with stability and delivery, resulting in inefficient antigen presentation and low response rates in patients with cancer. The purpose of this study was to develop a novel delivery approach for tumor antigenic peptides in order to elicit enhanced immune responses using poly(DL-lactide-co-glycolide) nanoparticles (PLGA-NPs) encapsulating tumor antigenic peptides. PLGA-NPs were made using the double emulsion-solvent evaporation method. Artificial antigen-presenting cells were generated by human dendritic cells (DCs) loaded with PLGA-NPs encapsulating tumor antigenic peptide(s). The efficiency of the antigen presentation was measured by interferon- $\gamma$ ELISpot assay (Vector Laboratories, Burlingame, CA). Antigenspecific cytotoxic T lymphocytes (CTLs) were generated and evaluated by CytoTox $96^{\circledR}$ Non-Radioactive Cytotoxicity Assay (Promega, Fitchburg, WI). The efficiency of the peptide delivery was compared between the methods of emulsification in incomplete Freund's adjuvant and encapsulation in PLGA-NPs. Our results showed that most of the PLGA-NPs were from $150 \mathrm{~nm}$ to $500 \mathrm{~nm}$ in diameter, and were negatively charged at $\mathrm{pH} 7.4$ with a mean zeta potential of $-15.53 \pm 0.71 \mathrm{mV}$; the PLGA-NPs could be colocalized in human DCs in 30 minutes of incubation. Human DCs loaded with PLGA-NPs encapsulating peptide induced significantly stronger CTL cytotoxicity than those pulsed with free peptide, while human DCs loaded with PLGA-NPs encapsulating a three-peptide cocktail induced a significantly greater CTL response than those encapsulating a two-peptide cocktail. Most importantly, the peptide dose encapsulated in PLGA-NPs was 63 times less than that emulsified in incomplete Freund's adjuvant, but it induced a more powerful CTL response in vivo. These results demonstrate that the delivery of peptides encapsulated in PLGA-NPs is a promising approach to induce effective antitumor CTL responses in vivo.

Keywords: peptide delivery, nanotechnology, dendritic cells, vaccination

\section{Introduction}

Tumor antigen-reactive T cells have been detected in the circulation of patients with cancer, ${ }^{1}$ evidencing the existence of a host immune response, which unfortunately fails to prevent disease progression in most cancer patients. It has been postulated that tumor-reactive $\mathrm{T}$ cells are in a nonresponsive state and low in number, and need to be activated to achieve an antitumor response. ${ }^{2} \mathrm{~T}$ lymphocytes recognize tumor antigens as small peptides of 8-10 amino acids in length, bound to cell surface molecules encoded by the major histocompatibility complex class I molecules. These major histocompatibility complex class I molecules are expressed in a number of cell types, including antigen-presenting cells (APCs). Dendritic cells (DCs) are widely 
distributed in peripheral tissues and lymphoid organs, they are believed to be the most potent APCs, and are specialized for the uptake of antigens, migration to lymph nodes, and activation of naïve T cells. ${ }^{3}$

In general, immunotherapy requiring an efficient $\mathrm{T}$ lymphocyte response is initiated by antigen delivery to APC. ${ }^{4}$ A large number of hydrophilic molecules are poorly taken up by cells since they do not efficiently cross the lipid bilayer of the plasma membrane. The low bioavailability of peptides, proteins, and nucleic acids is due to many factors, including poor stability and susceptibility to enzymes. ${ }^{5}$ This is considered to be a major limitation for their use as therapeutic agents in biomedical research and the pharmaceutical industry. Cytoplasmic delivery is particularly important for immunotherapy, because cytosolic peptides are transported across the endoplasmic reticulum membrane with the help of the ATP-dependent transporters associated with antigen processing. ${ }^{6}$ Peptides complexed with major histocompatibility complex class I molecules in the endoplasmic reticulum are then transported to the cell surface for recognition by cytotoxic $\mathrm{T}$ lymphocytes (CTLs). ${ }^{7}$ Peptide-based vaccines have been tested in clinical trials but have encountered very limited success due to difficulties associated with stability and delivery, resulting in inefficient antigen presentation. The overall objective clinical response rate of peptide vaccine trials is in the range of only $4 \%-8 \%{ }^{8-10}$ In order to improve the efficiency of peptide-based vaccines, there is a significant need to design novel peptide delivery systems capable of inducing more effective tumor antigen-specific CTLs.

Nanoparticles (NPs) have been used as adjuvants ${ }^{11}$ (added to a vaccine to augment immune responses toward antigens). Although the adjuvanticity of NPs is not completely understood, it has been suggested that NPs can enhance antigen uptake and/or stimulate APCs. ${ }^{12}$ NPs have gradually garnered a global reputation as an effective delivery system for therapeutic agents since they can be designed to slip between intercellular spaces, enter cells, or transport directly through biological barriers to access targeted sites. ${ }^{13,14}$ NPs also encapsulate therapeutic agents offering potential protection from enzymatic degradation, metabolism, and filtration. Poly(DL-lactide-co-glycolide) (PLGA) is a copolymer that allows controlled release of drug over time or in response to a biological cue. ${ }^{15}$ PLGA has many advantages over other polymers used in drug and gene delivery including biodegradability, biocompatibility, and approval for human use granted by the US Food and Drug Administration (FDA). ${ }^{16}$
We have successfully delivered plasmid DNA, ${ }^{17-19}$ drugs, ${ }^{13,19,20}$ and peptides ${ }^{21}$ by using PLGA-NPs in our previous work. In this report, we explore a novel strategy for effective peptide delivery that enhances the cytoplasmic delivery of peptides into DCs, eliciting a more robust tumor antigen-specific CTL response both in vitro and in vivo.

\section{Materials and methods Materials}

Poly(D,L-lactide-co-glycolide) (PLGA, molecular weight 23,000, copolymer ratio 50:50) was purchased from Birmingham Polymers, Inc (Birmingham, AL). Polyvinyl alcohol (PVA, average molecular weight 30,000-70,000), trifluoroacetic acid, acetonitrile, lipopolysaccharide, and L-15 (Leibovitz) medium were purchased from Sigma-Aldrich (St Louis, MO). Coumarin 6 was purchased from Polyscience, Inc (Warrington, PA). $\beta_{2}$-Microglobulin was purchased from EMD Biosciences, (San Diego, CA). Human serum albumin was purchased from Instituto Grifols (Barcelona, Spain). Granulocyte-macrophage colony-stimulating factor, interleukin (IL)-2, IL-4 and IL-7 were purchased from R and D (Minneapolis, MN). Monclonal human anti-interferon (IFN)- $\gamma$ antibody was purchased from Mabtech (Cincinnati, $\mathrm{OH}$ ). Hoechst 33342 was purchased from Invitrogen (Carlsbad, CA). CD8 MicroBeads were purchased from Miltenyi Biotec (Auburn, CA). All peptides used in this study were synthesized by GenScript Corp (Piscataway, NJ). HLA-A2 (+) blood was purchased from San Diego Blood Bank and Scripps Green Hospital (San Diego, CA). T2, EL4 and transgenic adenocarcinoma of mouse prostate (TRAMP)-C2 cell lines were purchased from ATCC (Manassas, VA). Melanoma cell lines (624 and 1351) and TIL2080 (human tumor infiltrating lymphocyte) were kindly provided by Dr John R Wunderlich (National Institutes of Health/National Cancer Institute, Bethesda, MD). ELISpot plates were purchased from Millipore (Billerica, MA). ELISpot substrate was purchased from Vector Laboratories (Burlingame, CA). Standard lactate dehydrogenase release assay was purchased from Promega (Madison, WI). All salts used in the preparation of buffers were from Fisher Scientific (Pittsburgh, PA). All aqueous solutions were prepared with distilled and deionized water (WaterPro Plus; Labconco, Kansas City, MO). C57BL/6 mice were purchased from Jackson Laboratory (Bar Harbor, ME).

\section{Formulation and characterization of PLGA-NPs}

NPs were formulated as previously described ${ }^{13}$ with minor modifications. In brief, $30 \mathrm{mg}$ PLGA and $600 \mu \mathrm{g}$ peptide 
(melanoma antigen recognized by T-cells [MART]-1: 27-35, AAGIGILTV; ${ }^{22}$ gp100: 154-162, KTWGQYWQV; ${ }^{23}$ gp100: 209-217, ITDQVPFSV; ${ }^{24}$ ovalbumin (OVA): 256-264, SIINFEKL, ${ }^{25}$ and mouse six-transmembrane epithelial antigen of the prostate (mSTEAP): 326-335, DVSKINRTEM ${ }^{26}$ ) in $1 \mathrm{~mL}$ of chloroform was emulsified in $6 \mathrm{~mL}$ of $2 \%$ PVA to form an oil-in-water emulsion. The emulsification was carried out using a micro-tip probe ultrasonic sonicator set at 55 watts

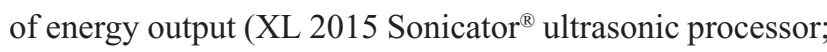
Misonix, Inc, Farmingdale, NY) for 2 minutes over an ice bath. The emulsion was stirred overnight on a magnetic stir plate to allow evaporation of chloroform and formation of PLGA-NPs. PLGA-NPs were recovered by ultracentrifugation at 30,000 rpm for 30 minutes at $4^{\circ} \mathrm{C}$ (Beckman Optima ${ }^{\mathrm{TM}}$ LE-80 K, Beckman Instruments, Palo Alto, CA), washed twice with sterile nano water to remove PVA and unencapsulated peptide, and then lyophilized for 48 hours (VirTis Company, Freeze Dryer, Gardiner, NY). To determine cellular uptake of PLGA-NPs, the formulation contained coumarin 6. The dye solution ( $50 \mu \mathrm{g}$ of coumarin 6 in $50 \mu \mathrm{L}$ chloroform) was added to the polymer solution prior to emulsification.

For measuring the size of the PLGA-NPs, samples were sputter coated with gold/palladium and imaged with a scanning electron microscope (Phillips XL30, FEI, OR). Size distribution was analyzed using MetaMorph (Version 7.1.0.0, Molecular Devices Inc, Sunnyvale, CA). Zeta potential of the PLGA-NPs was measured using the Zetasizer ${ }^{\circledR}$ Nano ZS90 (Malvern Instruments, Malvern, UK).

\section{Determination of peptide loading by high-performance liquid chromatography (HPLC)}

Peptides and peptide-loaded PLGA-NPs were identified using ultraviolet detection at $280 \mathrm{~nm}$. Briefly, $50 \mu \mathrm{L}$ of PLGA-NP suspension was injected into a Varian HPLC system (Varian, Walnut Creek, CA) equipped with a C18 reverse phase column $(8 \times 100 \mathrm{~mm}, 15 \mu \mathrm{m}$ particle size, pore size $300 \mathrm{~A}^{\circ}$ ) and a ultraviolet detector (Waters 486) set at $210 \mathrm{~nm}$ and a Gilson autoinjector (Mandel Scientific, Guelph, ON, Canada). The mobile phases employed were $10 \%$ ACN in water with $0.1 \%$ trifluoroacetic acid (Solvent A) and $70 \%$ ACN in water with $0.085 \%$ trifluoroacetic acid (Solvent B). The column was equilibrated with 75\% A and $25 \%$ B prior to each run. Samples were eluted on a linear gradient of $25 \%$ to $100 \% \mathrm{~B}$ over 12 minutes at a fixed flow rate of $0.8 \mathrm{ml} / \mathrm{min}$. The amount of peptide in each sample was calculated using a standard curve generated with known concentrations of the peptide.

\section{Generation of human DCs and intracellular uptake of PLGA-NPs}

Human DCs were generated by using enriched CD14+ monocytes from HLA-A2 (+) healthy donors purchased from San Diego Blood Bank and Scripps Green Hospital with the presence of granulocyte-macrophage colony-stimulating factor $(1000 \mathrm{U} / \mathrm{mL})$ and recombinant IL-4 $(400 \mathrm{U} / \mathrm{mL})$ for 7 days to produce immature DC (imDCs). Human imDCs at $50,000 / \mathrm{mL}$ were incubated with PLGA-NPs in medium $(100 \mu \mathrm{g} / \mathrm{mL})$ in a 12 -well plate for 30 minutes, respectively. Cells were then washed with cold phosphate buffered saline (PBS) to remove uninternalized PLGA-NPs. Cell nuclei were stained with trihydrochloride (Hoechst 33342; Invitrogen, Carlsbad, CA) and washed with PBS before subjected to fluorescence-activated cell sorting analysis and imaging by a confocal microscope (Leica TCS SP2; Leica Microsystems Inc, Buffalo Grove, IL).

\section{Antigen presentation by human mature DCs (mDCs) loaded with PLGA-NPs encapsulating MART-I}

Human imDCs at day 7 were incubated with control PLGANPs (empty-NPs), or PLGA-NPs encapsulating MART-1 peptide for 1 hour, followed by the addition of lipopolysaccharide for maturation. Mature DCs (mDCs) pulsed with MART-1 $(5 \mu \mathrm{g} / \mathrm{mL})$ served as the positive control. Test and control mDCs were cultured with TIL2080 cells at a ratio of 1:1 for 20 hours. The efficiency of the antigen presentation was measured by IFN- $\gamma$ ELISpot assay.

\section{ELISpot assay}

To test whether human mDCs loaded with PLGA-NPs encapsulating MART-1 present antigens more efficiently to T cells than do MART-1 peptide-pulsed human mDCs, IFN- $\gamma$ ELISpot assay was performed. Briefly, 96-well ELISpot plates were coated with $10 \mu \mathrm{g} / \mathrm{mL}$ monoclonal human antiIFN- $\gamma$ antibody (Mabtech) at $4^{\circ} \mathrm{C}$ overnight. The plates were then blocked with $10 \%$ human AB serum (Omega Scientific, Tarzana, CA) for 2 hours at $37^{\circ} \mathrm{C}$. Human mDCs $\left(2 \times 10^{4}\right)$ loaded with PLGA-NPs encapsulating MART-1 and MART-1 peptide-pulsed human mDCs (100 ng/mL) were incubated with TIL2080 cells, which recognize MART-1 peptide, at a ratio of 1:1 in CTL medium in the ELIspot plates at $37^{\circ} \mathrm{C}$ for 20 hours. All cultures were carried out in triplicate. The plates were developed using $100 \mu \mathrm{L} /$ well of substrate solution. Spots on the membrane were counted using automated image analysis system (CTL Analyzers LLC, Cleveland, $\mathrm{OH}$ ). 


\section{Generation of tumor antigen-specific CTLs} Human mDCs loaded with PLGA-NPs encapsulating peptides were used as the APCs. In brief, NP-loaded DCs were added to enriched $\mathrm{CD} 8^{+}$cells derived from HLA-A2 (+) donors at a ratio of 1 to 10 in CTL medium (RPMI 1640 with $10 \%$ human $\mathrm{AB}$ serum). IL-2 $(20 \mathrm{U} / \mathrm{mL})$ and IL-7 (30 U/ $\mathrm{mL}$ ) were added 3 days later. Restimulation was first carried out on day 7 as follows: $\beta_{2}$-microglobulin $(5 \mu \mathrm{g} / \mathrm{mL})$ and corresponding peptides $(5 \mu \mathrm{g} / \mathrm{mL})$ were added to irradiated autologous CD8 $8^{-}$cells and incubated for 2 hours at $37^{\circ} \mathrm{C}$. Four milliliters of L-15 (Leibovitz) medium containing 1\% human serum albumin, $\beta_{2}$-microglobulin and peptide was added to the adherent cells and incubated for 1.5 hours at $25^{\circ} \mathrm{C}$. Effector cells were added at $2 \times 10^{6}$ cells $/ \mathrm{mL}$ in fresh CTL medium. The second restimulation was carried out on day 14. On day 21 tumor antigen-specific CTLs were tested by ELISpot and cytotoxicity assay (CytoTox $96^{\circledR}$ Non-Radioactive Cytotoxicity Assay [Promega, Fitchburg, WI]).

\section{Cytotoxic assay}

$\mathrm{T} 2$ cells pulsed with corresponding peptides and melanoma cells were used as target cells to test peptide-specific CTLs. EL4 pulsed with OVA, or mSTEAP peptide and TRAMP$\mathrm{C} 2$ cells were used as target cells to test the immune response elicited by vaccination of PLGA-NPs encapsulating peptide and peptide emulsified in incomplete Freund's adjuvant (IFA). For cellular cytotoxicity assays, a standard lactate dehydrogenase release assay was performed according to the manufacturer's instructions. In brief, $2 \times 10^{4}$ target cells were added to the peptides-specific CTLs at the ratios of $1: 12.5$, $1: 25$, and 1:50 in a final volume of $100 \mu \mathrm{L}$. The plates were incubated for 3 hours and 15 minutes at $37^{\circ} \mathrm{C}$ after spin down. Ten microliters of $10 \times$ lysis buffer was added into the wells for maximum release, and incubation continued for $45 \mathrm{~min}$ utes at $37^{\circ} \mathrm{C}$. Fifty microliters of supernatant was transferred to a fresh ELISA plate after spin down and $50 \mu \mathrm{L}$ substrate was added to each well and mixed, and the plate was sealed. The mixture was incubated for 30 minutes at room temperature in the dark, and $50 \mu \mathrm{L}$ stop solution was added to each well. The plate was read at $490 \mathrm{~nm}$ and the specific lysis was calculated by the following formula: $\%$ Cytotoxicity $=100 \times$ (Experiment - Effector Spontaneous - Target Spontaneous)/ (Target Maximum - Target Spontaneous). ${ }^{27}$

\section{In vivo distribution of PLGA-NPs} after intraperitoneal (IP) injection

Coumarin 6-loaded PLGA-NPs were injected into C57BL $/ 6$ mice at $500 \mu \mathrm{g}$ in $500 \mu \mathrm{L}$ PBS by IP injection.
The mice were sacrificed 30 minutes after injection and imaged using the Olympus OV100 imaging system (Olympus Corp, Shinjuku-ku, Japan).

\section{Comparison of peptide delivery efficiency in vivo}

Peptide delivery efficiency was measured in vivo using mSTEAP (a mouse peptide with $80 \%$ homology to human STEAP ${ }^{28}$ ) and OVA peptide as test and positive control peptides, respectively. For free peptide immunization, $100 \mu \mathrm{g}$ of mSTEAP or OVA was emulsified in IFA and delivered via subcutaneous (SC) injection. IP injection was performed for empty-NP- and peptide- (both OVA and mSTEAP) loaded PLGA-NPs.

Thirty-five male C57BL/6 mice were randomized into the following five groups: (1) Control NP (empty-NP), (2) OVA emulsified in IFA (OVA + IFA), (3) mSTEAP emulsified in IFA (mSTEAP + IFA), (4) PLGA-NPs encapsulating OVA, and (5) PLGA-NPs encapsulating mSTEAP. All mice were immunized once on day 0 (Table 1). Ten days after immunization, three mice in each group were sacrificed followed by in vivo restimulation of splenocytes with the same peptides used for priming. Cytolytic activity of the CTLs was assayed 6 days after restimulation ${ }^{27}$ using a standard cytotoxic assay with the following targets: (1) EL-4 cells; (2) EL-4 cells pulsed with OVA peptide; (3) EL-4 cells pulsed with mSTEAP peptide; and (4) TRAMP-C2 cells.

\section{Tumor size in immunized mice after challenge}

Four C57BL/6 mice immunized in each group were challenged with $1 \times 10^{6}$ of TRAMP-C2 on day 10 via SC

Table I Vaccination of C57BL/6 mice in different groups

\begin{tabular}{lll}
\hline Mice groups & Vaccination & $\begin{array}{l}\text { Routes } \\
\text { of injection }\end{array}$ \\
\hline I. Empty-NPs & $\begin{array}{l}500 \mu \mathrm{g} \text { empty-NPs } \\
\text { in } 500 \mu \mathrm{L} \text { of PBS } \\
\text { 100 } \mu \mathrm{g} \text { OVA peptide } \\
\text { in IFA of I00 } \mu \mathrm{L}\end{array}$ & IP \\
2. OVA + IFA & $\begin{array}{l}500 \mu \mathrm{g} \text { PLGA-NPs-OVA } \\
\text { in PBS of } 500 \mu \mathrm{L}\end{array}$ & IP \\
3. OVA + NPs & $\begin{array}{l}100 \mu \mathrm{g} \text { mSTEAP peptide } \\
\text { in IFA of I00 } \mu \mathrm{L}\end{array}$ & SC \\
4. mSTEAP + IFA & $\begin{array}{l}500 \mu \mathrm{g} \text { PLGA-NPs-mSTEAP } \\
\text { in PBS of } 500 \mu \mathrm{L}\end{array}$ & IP \\
\hline 5. mSTEAP + NPs &
\end{tabular}

Abbreviations: NPs, nanoparticles; PBS, phosphate-buffered saline; IP, intraperitoneal injection; OVA, ovalbumin; IFA, incomplete Freund's adjuvant; SC, subcutaneous injection; PLGA, poly(DL-lactide-co-glycolide); mSTEAP, mouse six-transmembrane epithelial antigen of the prostate. 
injection in the right flank, and tumor size was monitored with a digital caliper (Thermo Fisher Scientific, Pittsburgh, PA) every 3 days.

\section{Statistical analysis}

$P$-values were calculated to test the statistical significance between the groups of free peptides and PLGA-NPs encapsulating peptides using two-tailed unpaired Student's $t$-test. The confidence interval was set at $95 \%$ and a $P$ value of $<0.05$ was accepted as significant (*); $P<0.01$ (**), $P<0.001$ (***).

\section{Results}

\section{Characterization of peptide-loaded PLGA-NPs}

NPs are colloidal systems with a size range typically from 1 to $1000 \mathrm{~nm}$ in diameter. They are formulated from a polymer, in which the therapeutic agents were entrapped in the polymer matrix. The double emulsion-solvent technique is the most commonly used method to formulate polylactic acid (PLA) and PLGA NPs, with PVA to stabilize the emulsion. PLGA-NPs were sputter coated with gold/palladium and imaged using a scanning electron microscope under
$20 \mathrm{kV}$ (Figure 1A) and $10 \mathrm{kV}$ (Figure 1B), respectively. The unfractionated PLGA-NPs demonstrated a size distribution range from $70 \mathrm{~nm}$ to $795 \mathrm{~nm}$, and $78 \%$ of these PLGA-NPs are from $150 \mathrm{~nm}$ to $500 \mathrm{~nm}$ in diameter (Figure 1C). The PLGA-NPs were negatively charged at $\mathrm{pH} 7.4$ with a mean zeta potential of $-15.53 \pm 0.71 \mathrm{mV}$ (Figure $1 \mathrm{D}, \mathrm{n}=3$ ), and the polydispersity index (PDI) is $0.308 \pm 0.034(n=3)$ when analyzed by Zetasizer Nano ZS90. The size and potential of the PLGA-NPs used in this study varied slightly between batches, and also varied according to the different peptide(s) encapsulated. MART-1 and gp100:154-162 peptide-loaded PLGA-NPs are the representatives, which were used in the characterization of the PLGA-NPs in Figure 1.

\section{Peptide loading and encapsulation in PLGA-NPs}

Controlling both the drug-loading efficiency and particle size of the drug-loaded NPs is very important when using NPs as drug delivery systems. ${ }^{29}$ To measure the peptide loading and encapsulation efficiency, we defined peptide loading as the peptide present $(\mu \mathrm{g})$ in $1 \mathrm{mg}$ PLGA-NPs, and the encapsulation efficiency stands for the percentage
A

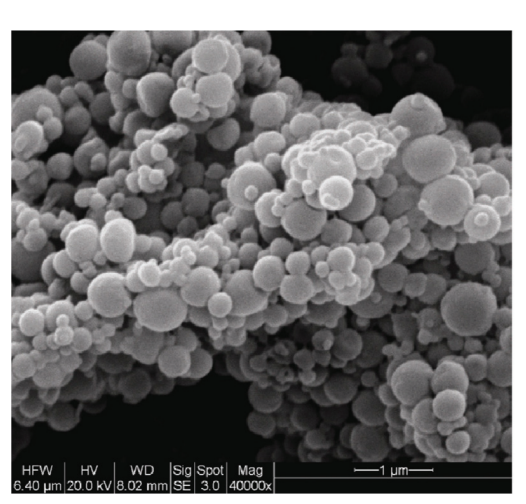

C

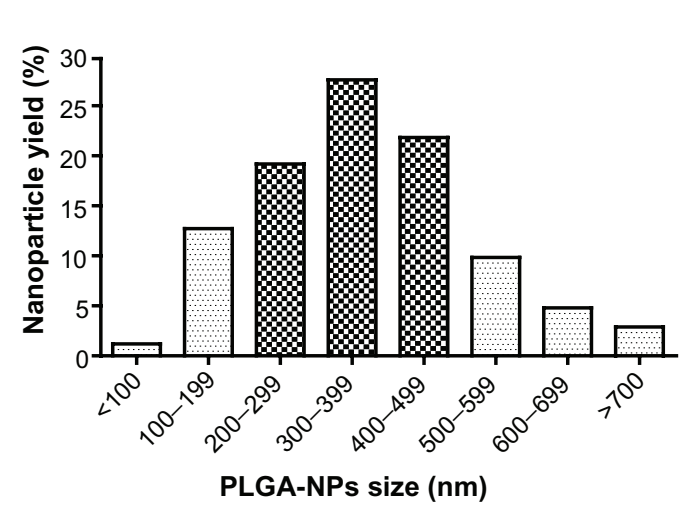

D
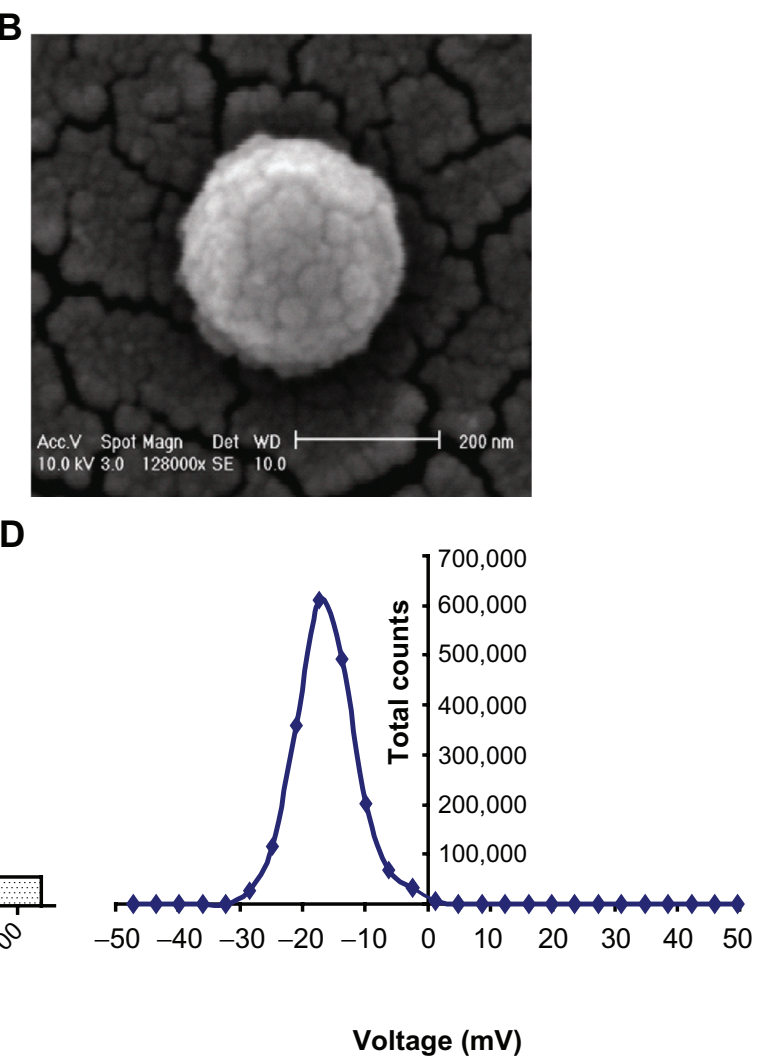

Figure I Characterization of PLGA-NPs. Images were taken by a scanning electron microscope (Phillips XL 30, FEl, OR). (A) Under 20 kV (40,000×). (B) under I0 kV $($ I 28,000 $)$. (C) Size range of unfractionated PLGA-NPs. (D) Zeta potential of PLGA-NPs.

Abbreviation: PLGA-NPs, poly(DL-lactide-co-glycolide) nanoparticles. 
of peptide entrapped in PLGA-NPs over the initial amount of loaded peptide. Based on these definitions and the HPLC-analyzed results, the PLGA-NP peptide loading is $3.176 \pm 0.144 \mu \mathrm{g}(\mathrm{n}=3)$, and the peptide encapsulation efficiency $(\%)$ is $82.34 \% \pm 8.4 \%(n=3)$.

\section{Cellular uptake of PLGA-NPs in human DCs}

Next, we studied whether the NP-loaded DCs could present the antigenic peptides to T cells more efficiently, leading to the induction of antigen-specific CTLs for immunotherapy. Coumarin 6 loaded PLGA-NPs were incubated with human imDCs for 1 hour and cell nuclei were stained with Hoechst 33342. Images were taken under a confocal microscope, as shown in Figure 2A (4',6-diamidino-2-phenylindole channel), Figure 2B (fluorescein isothiocyanate channel), Figure 2C (both 4',6-diamidino-2-phenylindole and fluorescein isothiocyanate channels overlaid), and Figure 2D (4',6-diamidino-2-phenylindole, fluorescein isothiocyanate, and reflection channels overlaid). Fluorescent signals were seen in the cytoplasm of human imDCs. To test uptake efficiency, human imDCs were next incubated with coumarin 6-loaded PLGA-NPs for 30 minutes, and washed twice with Hank's buffered salt solution to remove uninternalized PLGA-NPs for fluorescence-activated cell sorting analysis. The result showed that $100 \%$ of human DCs were fluorescent positive (Figure 2E).

\section{Antigen presentation comparison between human mDCs loaded with PLGA-NPs encapsulating peptide and those pulsed with free peptide}

MART-1 peptide is the most well characterized and most commonly used epitope in melanoma studies, and is the target of tumor-infiltrating lymphocytes. ${ }^{30}$ TIL2080 cell line was used as effector cells to recognize and kill human mDCs loaded with PLGA-NPs encapsulating MART-1, or MART-1 peptide-pulsed human $\mathrm{mDCs}$ while being the target cells. The results showed that human mDCs loaded with PLGA-NPs encapsulating MART-1 presented more MART-1 peptides to TIL2080 cells than those pulsed with MART-1 peptide,
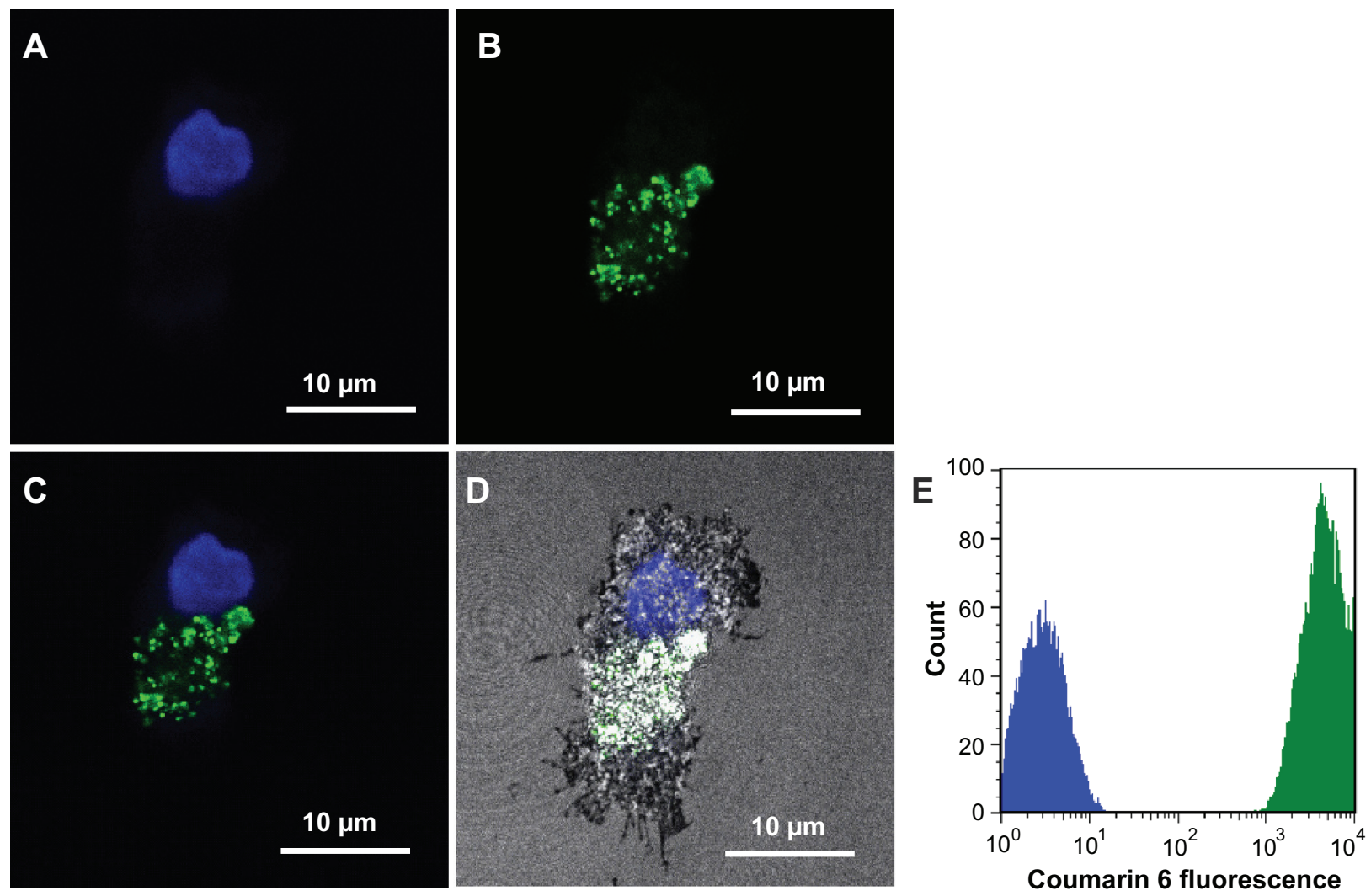

Figure 2 Colocalization of poly(DL-lactide-co-glycolide) nanoparticles in human dendritic cells. Images were taken under a confocal microscope. (A) 4',6-Diamidino-2phenylindole channel. (B) Fluorescein isothiocyanate channel. (C) 4',6-Diamidino-2-phenylindole and fluorescein isothiocyanate channels overlaid. (D) 4',6-Diamidino-2phenylindole, fluorescein isothiocyanate, and reflection channels overlaid. (E) Fluorescence-activated cell sorting analysis result. 

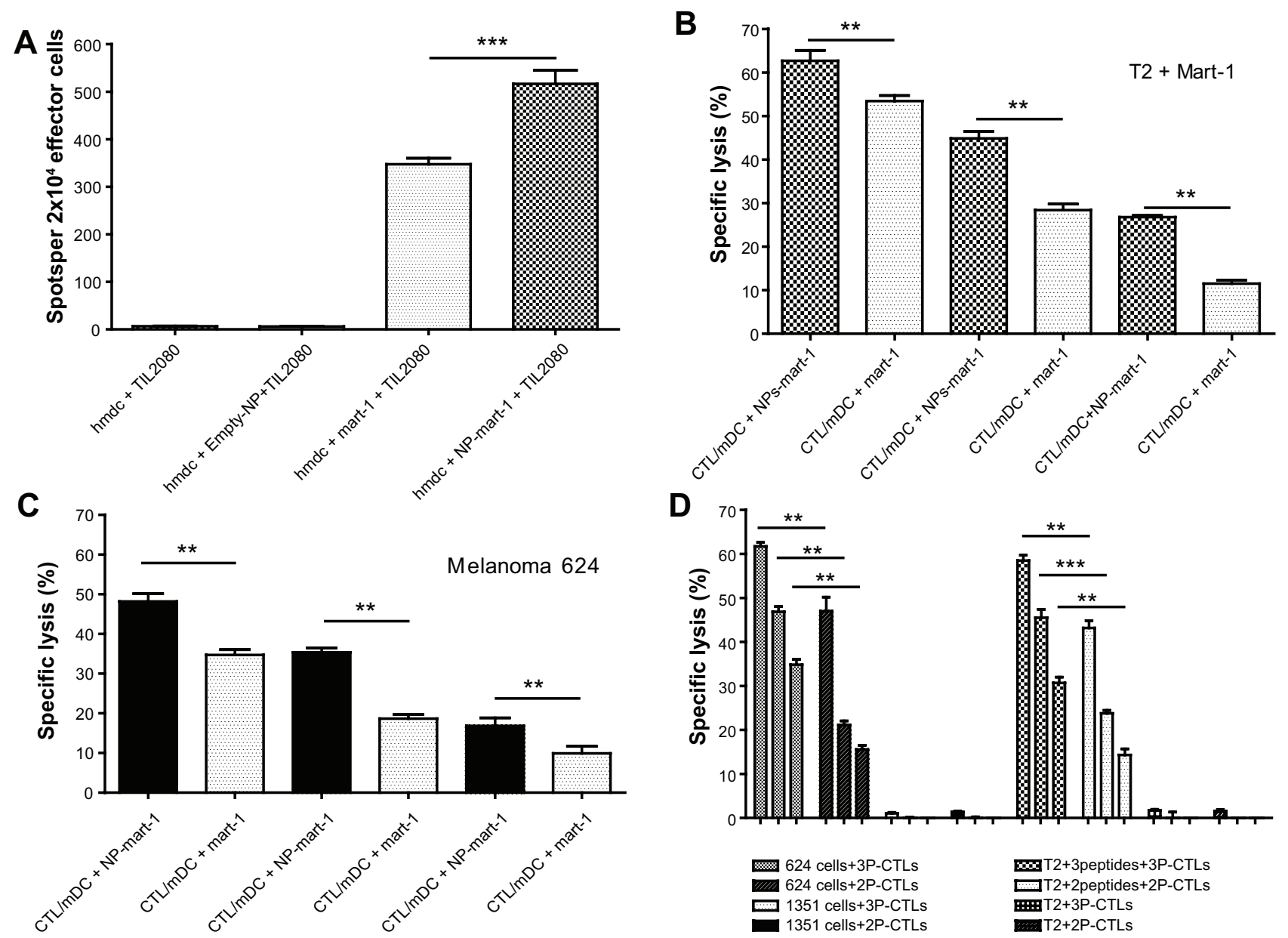

Figure 3 Enhanced antigen presentation and cytotoxic T lymphocyte (CTL) activity comparison. (A) ELISpot assay to test interferon- $\gamma$ release when human mature dendritic cells presented melanoma antigen recognized by T-cell (MART)-I peptide to TIL2080 cells. (B) CTL activity comparison between the CTLs generated by human mature dendritic cells loaded with NPs encapsulating MART-I peptide and free MART-I peptide-pulsed human mature dendritic cells when the target cells were T2 cells pulsed with MART-I peptide. (C) CTL activity comparison when the target cells were melanoma 624 cells. (D) Cytotoxic activity comparison of the CTLs generated by poly (DL-lactide-co-glycolide nanoparticles encapsulating the two-peptide (MART-I:27-35 and gpI00:154-162) and three-peptide (MART-I:27-35, gPI00:I54-I62, and gPI00: 209-217) cocktails.

Notes: The confidence interval was set at $95 \%$ and a $P$ value of $<0.05$ was accepted as significant; $* * P<0.01$, ***P $<0.001$.

Abbreviations: CTL, cytotoxic T lymphocyte; PLGA-NPs, poly(DL-lactide-co-glycolide) nanoparticles; hmDC, human mature dendritic cells.

resulted in more release of IFN $\gamma$, as measured by ELISpot assay (Figure 3A, $P=0.0003$ ).

\section{Comparison of CTL cytotoxic activities}

The cytototoxic activity of tumor antigen-specific CTLs generated by using both human mDCs loaded with PLGANPs encapsulating MART-1 and human mDCs pulsed with MART-1 peptide were tested using cytotoxic assays. All the CTLs generated using the above methods killed both T2 cells pulsed with MART-1 (Figure 3B) and melanoma 624 cells (Figure 3C). The results demonstrated that the cytototoxic activity of the tumor antigen-specific CTLs generated by human mDCs loaded with PLGA-NPs encapsulating MART-1 peptide (CTL/mDC + NP-MART-1) was significantly greater than that generated by human $\mathrm{mDCs}$ pulsed with free peptide
(CTL/mDC + MART-1) when the ratio of effector/target was both 50/1 and 25/1 (Figure 3B and C). The cytototoxic activity of CTL/mDC + NP-MART-1 was still significantly stronger than CTL/mDC-MART-1 when the ratio of effector/target was 12.5/1 while the targets were MART-1-pulsed T2 cells (Figure 3B), along with targets that were melanoma 624 cells (Figure 3C). However, these CTLs could not recognize and kill 2 cells and 1351 melanoma cells due to lack of MART-1 antigen expression on their cell surfaces (data not shown).

Most interestingly, the CTLs induced by human mDCs loaded with PLGA-NPs encapsulating a three-peptide cocktail (3P, including MART-1:27-35, gp100:154-162 and gp100: 209-217) generated significantly more robust cytotoxic activity than those encapsulating a two-peptide cocktail (2P, including MART-1:27-35 and gp100:154-162) when the 
targets were melanoma 624 cells and T2 cells pulsed with the peptide-cocktails at any effector/target ratio (Figure 3D, $P<0.01)$. These CTLs are not able to recognize and kill 1351 melanoma cells and T2 cells owing to lack of antigen expression on their cell surfaces (Figure 3D).

\section{Distribution of the PLGA-NPs in vivo after IP injection}

The three main types of professional APCs are macrophages, DCs, and B cells. Macrophages are predominantly located in the lungs, liver, neural tissue, bone, and spleen; imDCs are mostly located in the epithelium of the skin, the gastrointestinal tract and the respiratory tract. Most of the B cells are located in bone marrow and spleen. Thus, these organs were chosen for the biodistribution study. Fluorescent signals were compared between the blank control mouse and the mouse dosed with $500 \mu \mathrm{g}$ coumarin 6-loaded PLGA-NPs 30 minutes after IP injection. Scattered fluorescent particles were seen under the skin all over the mouse body, and these signals were also seen in the kidney, brain, pancreas, spleen, heart, lung, and liver (Figure 4B), but were not seen in the blank control mouse, apart from autofluorescence in the paws and intestine (Figure 4A). Enlarged images clearly showed that the fluorescent PLGA-NPs are distributed to various organs, including the intestine, brain, lung, and pancreas (Figure 4C).
A Blank control
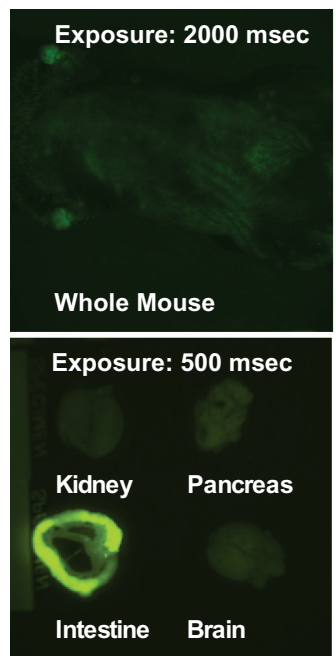

Exposure: 500 msec

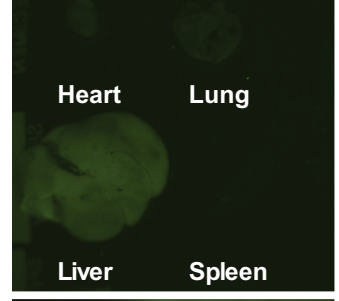

Exposure: $120 \mathrm{msec}$

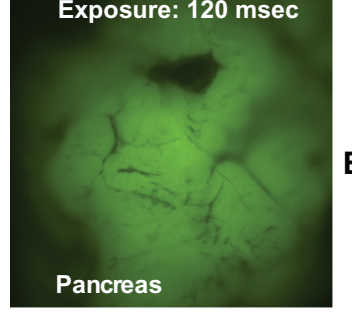

B $500 \mu g$ PLGA-NPs

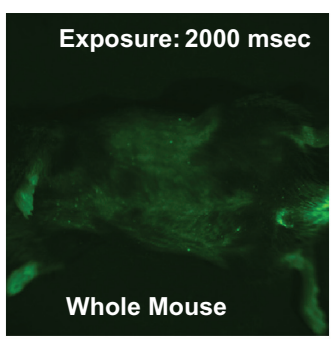

Exposure: 500 msec

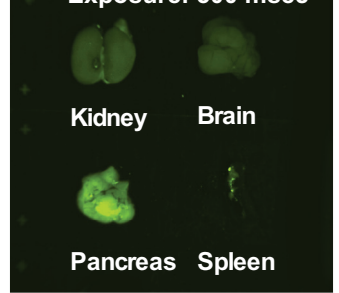

Exposure: 500 msec

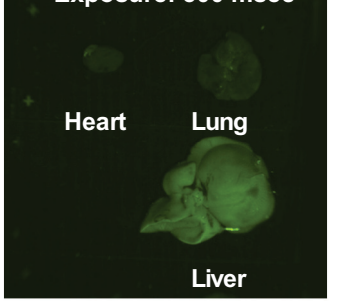

Blank control vs $1000 \mu g$ PLGA-NP IP
$500 \mu \mathrm{g}$ PLGA-NPs (high power images)
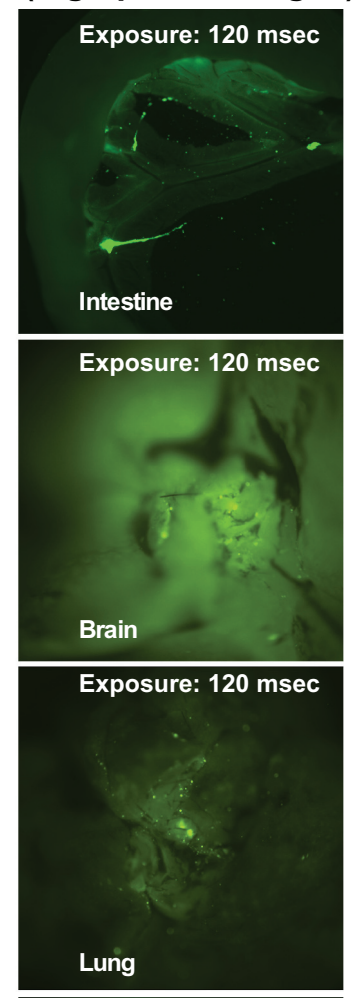

Exposure: $120 \mathrm{msec}$

Figure 4 Distribution of poly(DL-lactide-co-glycolide) nanoparticles in vivo after intraperitoneal injection. (A) Blank control mouse. (B) Test mouse dosed with $500 \mu \mathrm{g}$ poly(DL-lactide-co-glycolide) nanoparticles (PLGA-NPs) 30 minutes after intraperitoneal injection. (C) High-power mouse organ images. Coumarin 6-loaded poly(DL-lactideco-glycolide) nanoparticles were injected into C57BL/6 mice at $500 \mu \mathrm{g}$ in $500 \mu \mathrm{L}$ phosphate-buffered saline by intraperitoneal injection.

Note: The mice were sacrificed 30 minutes after injection and imaged using the Olympus OVI00 imaging system (Olympus Corp, Shinjuku-ku, Japan). 


\section{Tumor suppression in mice immunized with PLGA-NPs encapsulating mSTEAP peptide}

Based on observation records, tumor size measurement, and statistical data, delayed tumor development was observed in mice immunized with PLGA-NPs encapsulating mSTEAP peptide, and the tumor size was significantly smaller than in those in the control group immunized with empty-NP $(P=0.019$, Figure 5A). The difference in tumor size between the mice immunized with $\mathrm{mSTEAP}$ peptide emulsified in IFA and PBS was not significant ( $P=0.361$, Figure 5A). Tumor size difference between the mice immunized with PLGA-NPs encapsulating mSTEAP peptide and those immunized with mSTEAP peptide emulsified in IFA did not reach significance, but there was a trend to smaller tumor size $(P=0.123)$ in the former.

\section{A}

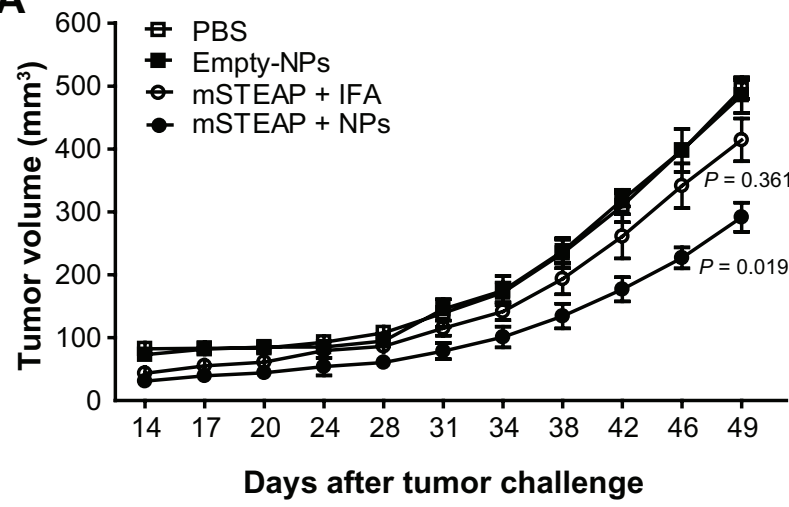

C

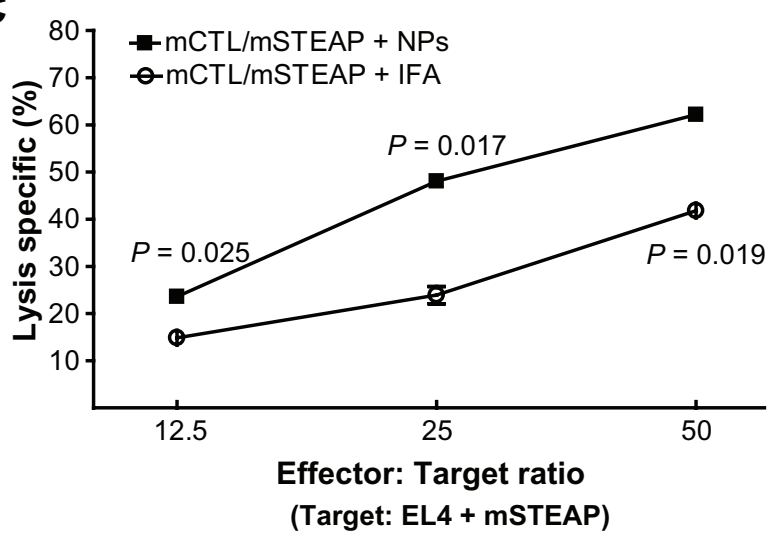

\section{PLGA-NPs encapsulating peptides} induce a significantly stronger antitumor response

We next sought to address the question of whether PLGANPs encapsulating peptides can be taken up by professional APCs (DCs, macrophages, and B cells) in vivo, which can then present the loaded peptides to $T$ cells, and eventually induce an effective immune response. To answer this, 35 male C57BL/6 mice were immunized with their corresponding agents only once followed by in vitro restimulation of splenocytes with the same peptides used for priming. We evaluated the lysis patterns of each agent on target cells. The results showed that mouse CTLs derived from the mice immunized with empty-NPs, if pulsed with SIINFEKL peptide (OVA, $5 \mu \mathrm{g} / \mathrm{mL}$ ) in vitro, were able to recognize and kill EL4 cells pulsed with OVA ( $\bullet$ in Figure 5B).
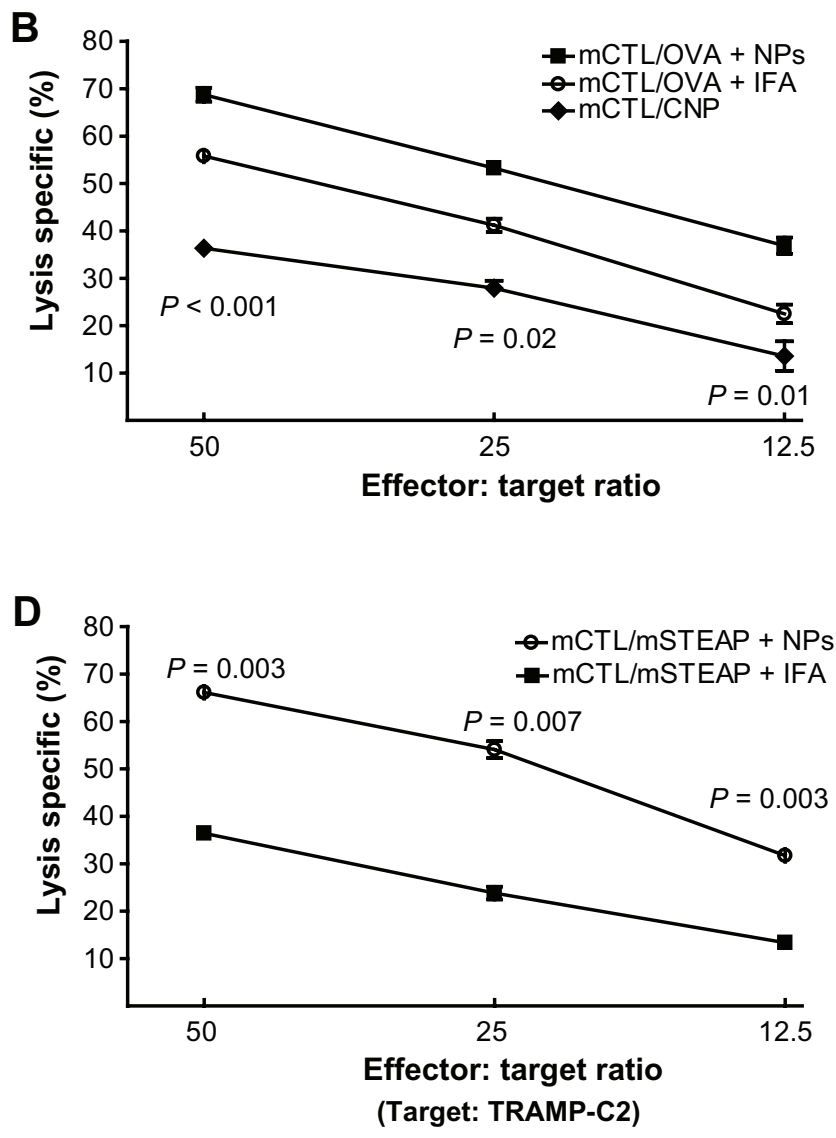

Figure 5 Immunization with PLGA-NPs encapsulating mSTEAP peptide elicited stronger immune response. (A) Tumor suppression was observed in the mice immunized with PLGA-NPs encapsulating mouse six-transmembrane epithelial antigen of the prostate (mSTEAP) peptide $(\bullet)$ when compared with mSTEAP peptide emulsified in incomplete Freund's adjuvant (O). (B) Ovalbumin (OVA)-specific CTLs derived from the mice immunized with PLGA-NPs encapsulating OVA lysed a significantly higher percentage of EL4 cells pulsed with OVA than those immunized with OVA emulsified in IFA ( $\mathbf{\square}$ vs $O)$. The CTLs derived from the mice immunized with empty-NP against EL4 cells pulsed with OVA $(\diamond)$. Mice immunized with PLGA-NPs encapsulating mSTEAP peptide induced a more effective immune response, not only lysed significantly higher percentages of EL4 cells pulsed with mSTEAP peptide (C), but transgenic adenocarcinoma of mouse prostate-C2 cells than those derived from the mice immunized with mSTEAP emulsified in incomplete Freund's adjuvant (D).

Abbreviation: PLGA-NPs, poly(DL-lactide-co-glycolide) nanoparticles. 
CTL activity in the mice immunized with PLGA-NPs encapsulating peptides was significantly higher than in those immunized with peptides emulsified in IFA. The difference in CTL activity between the groups of OVA + PLGA-NPs and OVA + IFA was $68.76 \%$ vs $55.19 \%(P=0.0007), 53.25 \%$ vs $39.05 \%(P=0.0185)$ and $34.58 \%$ vs $20.74 \%(P=0.0110)$ when the effector/target ratio was 50/1, 25/1 and 12.5/1, respectively, while the target cells were EL4 cells pulsed with OVA peptide (Figure 5B).

We also compared the CTL activity between the groups of mSTEAP + PLGA-NPs and mSTEAP + IFA; the difference was $62.19 \%$ vs $41.81 \%(P=0.025), 48.07 \%$ vs $23.91 \%$ $(P=0.017)$, and $23.6 \%$ vs $14.85 \%(P=0.019)$ when the effector/target ratio was $50 / 1,25 / 1$ and $12.5 / 1$, respectively, while the target cells were EL4 cells pulsed with mSTEAP peptide (Figure 5C). When the target cells were TRAMP-C2 cells, the difference in CTL activity was $66.12 \%$ vs $36.41 \%$ ( $P=0.003), 54.07 \%$ vs $23.79 \%(P=0.007)$, and $31.73 \%$ vs $13.35 \%(P=0.003)$ while the effector/target ratio was $50 / 1$, $25 / 1$ and 12.5/1, respectively (Figure 5D).

Most importantly, the peptide dose encapsulated in PLGA-NPs was 63 times less than that emulsified in IFA, but it induced a more robust CTL response. The lysis capacity of the CTLs induced by PLGA-NPs encapsulating mSTEAP peptide was $1.82-2.22$-fold higher when the effector/target ratio was $12.5 / 1$ to $50 / 1$ than of the CTLs induced by mSTEAP peptide emulsified in IFA while the targets were TRAMP-C2 cells.

\section{Discussion}

The successful generation of an effective immune response against tumor cells is a prerequisite for any immunotherapeutic strategy for cancer. ${ }^{31}$ Boosting the immune system with tailored immunotherapies provides a promising alternative to standard chemo- and radiotherapy and will ideally yield a specific anticancer response with fewer side effects. ${ }^{32}$ In the field of cancer immunotherapy, most enthusiasm has been directed to the use of cancer vaccines. ${ }^{8}$ Peptide-based vaccines are more attractive than other forms including whole cell vaccines, protein vaccines, and DNA-based vaccines. However, one difficulty for peptide-based vaccines is their rather poor immunogenicity, ${ }^{33}$ thus, appropriate adjuvants are greatly needed to make them more potent in eliciting effective $\mathrm{T}$ cell responses.

IFA serves as a conventional carrier for peptide delivery, yet the response rate of peptide emulsified in IFA trials in 246 individuals was only $3.66 \%{ }^{8}$ To improve cancer prevention and treatment, specific immune-activating strategies must be investigated. Adjuvants are usually pharmacological or immunological agents which modify the effect of other agents (eg, drugs or vaccines) while having few, if any, direct effects when given alone. For standard prophylactic immunization in healthy individuals, only adjuvants that induce minimal side effects will prove to be acceptable. Adjuvants for cancer vaccines, nevertheless, need to be very potent, which may increase their toxicity and the induction of autoimmune reactions. ${ }^{34}$ Particulate vaccine carriers offer a good balance between adjuvanticity and safety. In this study, we demonstrated that peptide-loaded PLGA-NPs mediated efficient peptide delivery to APC and induced tumor antigen-specific CTLs and effective prophylactic immune responses in vivo.

Particulate adjuvants have comparable dimensions to the pathogens recognized by the immune system $(<5 \mu \mathrm{m})$, which offers a great advantage in vaccine technology. ${ }^{35}$ Particles are internalized by APCs via different mechanisms, depending on their size. ${ }^{36}$ Particles of $20-200 \mathrm{~nm}$ are usually taken up via endocytosis by DCs, while those of $0.5-5 \mu \mathrm{m}$ are primarily taken up by macrophages via macropinocytosis or phagocytosis. ${ }^{32}$ We demonstrated by fluorescence-activated cell sorting that PLGA-NPs could be taken up by $100 \%$ of human DCs within 30 minutes after incubation. Importantly, more effective tumor antigen-specific CTLs were induced by using human DCs loaded with PLGA-NPs encapsulating peptide than human DCs pulsed with free peptide.

From our study of the distribution of PLGA-NPs after IP injection, we found that fluorescent PLGA-NPs are present in various organs, including the liver, spleen, brain, lung, etc (Figure 4B and C). It was reported that PLGA NPs of $105 \mathrm{~nm}$ were present in the blood at higher concentrations for up to 24 hours and were able to reduce their uptake by the reticuloendothelial system, compared with that of etoposide-loaded PLGA NPs of $160 \mathrm{~nm}$ and pure drug. ${ }^{37}$ For therapeutic targeting, PLGA-NPs should evade the reticuloendothelial system to achieve highest drug delivery efficiency. For example, PLGA-NPs of size $100 \mathrm{~nm}$ can be used for long-term circulation without the need for surface modification, ${ }^{38}$ and the nanocarriers must be hidden from the reticuloendothelial system because it could destroy any foreign material through opsonization, followed by phagocytosis by macrophages..$^{39,40}$ The most important finding of our study is the in vivo targeting of the APCs, which could phagocytize the antigen-loaded PLGA-NPs after IP administration and present the antigens to naïve $\mathrm{T}$ cells for generating an effective immune response. Interestingly, we found that PLGA-NPs cross the blood-brain barrier (BBB) 
in our study; another group also reported that the PLGANPs were concentrated mainly in the hippocampus. ${ }^{41}$ The mechanism might be taking advantage of the leaky vessel walls by passive diffusion or convection, dependent on the hydrostatic and osmotic pressure differences between blood and interstitial space.

Among different polymers, PLGA and PLA have been extensively used as NP carriers in controlled-release delivery systems for many bioactive molecules due to their low toxicity, good bioavailability and biocompatibility, and FDA approval status. The bioactive molecules delivered include drugs, ${ }^{13,42-44}$ proteins,,${ }^{45,46}$ DNA, ${ }^{47-49}$ and oligonucleotides.${ }^{50-52}$ Only a few studies have shown peptide delivery by PLGANPs to elicit a type $1 \mathrm{~T}$ helper immune response..$^{53-55} \mathrm{We}$ used the same PLGA polymer and double emulsion-solvent evaporation method, but a different protocol and with entrapped peptides, thus producing PLGA-NPs products with different characteristics including size, potential and polydispersity, etc. In other studies, particle size ranged from 1 to $10 \mu \mathrm{m},{ }^{56} 350$ to $410 \mathrm{~nm},{ }^{55}$ and 290 to $350 \mathrm{~nm}^{57}$ in diameter. Encapsulation efficiency was $23 \%$ for OVA peptide ${ }^{56}, 5.2 \% \pm 0.6 \%$ for TRP $2,{ }^{55}$ and $67.3 \% \pm 6.9 \%$ for 7-acyl lipid A, ${ }^{55}$ and the peptide loading was $0.03 \mu \mathrm{g}$ for OVA peptide,${ }^{56} 0.94 \pm 0.11 \mu \mathrm{g}$ for TRP $2,{ }^{55}$ and $1.79 \pm 0.18 \mu \mathrm{g}$ for 7 -acyl lipid A, ${ }^{55}$ respectively. Our results showed a size range for unfractionated PLGA-NPs from $70 \mathrm{~nm}$ to $795 \mathrm{~nm} ; 78 \%$ of these PLGA-NPs sized from $150 \mathrm{~nm}$ to $500 \mathrm{~nm}$ in diameter. Based on HPLC-analyzed results, our peptide loading was $3.176 \pm 0.144 \mu \mathrm{g}(\mathrm{n}=3)$, and the peptide encapsulation efficiency was $82.34 \% \pm 8.4 \%(n=3)$. Our data are consistent with above results, but the peptide loading and encapsulation efficiency of our PLGA-NP products was much higher than that of other authors. These differences may be due to a more optimized delivery system because we found the PLGA-NPs, which were loaded with more peptide (1 mg/batch), did not function better than those loaded with less peptide $(600 \mu \mathrm{g} / \mathrm{batch}$, data not shown).

For tumor antigen-specific CTL induction, Hamdy et al utilized C57BL/ 6 mice immunized SC with $10 \mu \mathrm{g}$ tyrosinaserelated protein-2 (TRP2) encapsulated in PLGA-NPs, versus mice who received $10 \mathrm{mg}$ plain PLGA-NPs (empty-NPs) SC on day 0 , and boosted on day $11 .{ }^{55}$ Their results showed activated TRP2-specific $\mathrm{CD} 8^{+} \mathrm{T}$ cell responses in the draining lymph nodes and spleen of mice immunized with PLGANPs encapsulating TRP $2 .{ }^{55}$

In our study, the mice were immunized only once with $500 \mu \mathrm{g}$ PLGA-NPs encapsulating $1.588 \mu \mathrm{g}$ mSTEAP peptide, $500 \mu \mathrm{g}$ control PLGA-NPs by IP injection, or $100 \mu \mathrm{g}$
mSTEAP peptide emulsified in $100 \mu \mathrm{L}$ IFA by SC injection. Most importantly, the peptide dose encapsulated in PLGANPs was 63 times less than that emulsified in IFA, but it induced more robust CTLs with the lysis rate of $66.12 \%$ vs $36.41 \% ; 55.075 \%$ vs $24.795 \%$, and $31.73 \%$ vs $14.85 \%$ when the target cells were TRAMP-C2 cells, and the effector/target ratio was 50/1, 25/1, and 12.5/1, respectively (Figure 5D). We found that tumors in the mice immunized with PLGANPs encapsulating mSTEAP developed later and were significantly smaller than tumors in the mice immunized with mSTEAP + IFA $(P=0.019)$. CTL activity in the mice immunized with PLGA-NPs encapsulating peptide was much higher than that in the mice immunized with peptide emulsified in IFA.

Antigen presentation is a crucial step in the initiation of an effective immune response. DCs have a unique ability to efficiently present antigens and thus play a central role in the orchestration of the adaptive immune response. This has made these cells a major focus of interest in the conception of immunotherapeutic vaccine strategies. An immunization strategy using PLGA-NPs encapsulating antigenic peptides is an efficient approach for antigen presentation that induces more effective tumor antigen-specific immune responses than free peptide emulsified in IFA. These findings provide a good rationale for using PLGA-NPs as competent carriers for future peptide-based cancer vaccine formulations.

\section{Conclusion}

The majority of the PLGA-NPs made in this study measured from $150 \mathrm{~nm}$ to $500 \mathrm{~nm}$ in diameter, and the mean zeta potential was $-15.53 \mathrm{mV}$. The PLGA-NPs were able to be colocalized in human DCs within 30 minutes of incubation. As the APCs, human DCs loaded with PLGA-NPs encapsulating peptide induced a significantly stronger CTL cytotoxicity than those pulsed with free peptide in vitro. Much higher efficiency of peptide delivery (63 times) was found in PLGA-NPs when compared with IFA. PLGA-NPs, as a peptide carrier, induce a more powerful CTL response in vivo. These findings are fundamental for the development of peptide vaccines, and the induction of an effective immune response for cancer immunotherapy.

\section{Acknowledgments}

This work was supported by grants from the Department of Defense PC041024 (B. Minev), and NCI grants U54CA132384 and U54CA132379 (Minev/Grotjahn), and RO1CA154256 (Minev/Kruse). The authors would like to thank Ronnie Fang and Liangfang Zhang at UCSD Moores 
Cancer Center for their excellent help on the characterization of the PLGA-NPs.

\section{Disclosure}

The authors declare that they have no competing financial interests in this work.

\section{References}

1. Rosenberg SA. Progress in human tumour immunology and immunotherapy. Nature. 2001;411(6835):380-384.

2. Sloan JM, Kershaw MH, Touloukian CE, et al. MHC class I and class II presentation of tumor antigen in retrovirally and adenovirally transduced dendritic cells. Cancer Gene Ther. 2002;9(11):946-950.

3. Steinman RM. Lasker Basic Medical Research Award. Dendritic cells: versatile controllers of the immune system. Nat Med. 2007;13(10): 1155-1159.

4. Epaulard O, Toussaint B, Quenee L, et al. Anti-tumor immunotherapy via antigen delivery from a live attenuated genetically engineered Pseudomonas aeruginosa type III secretion system-based vector. Mol Ther. 2006;14(5):656-661.

5. Murthy N, Campbell J, Fausto N, Hoffman AS, Stayton PS. Bioinspired $\mathrm{pH}$-responsive polymers for the intracellular delivery of biomolecular drugs. Bioconjug Chem. 2003;14(2):412-419.

6. Spies T, Cerundolo V, Colonna M, Cresswell P, Townsend A, DeMars R. Presentation of viral antigen by MHC class I molecules is dependent on a putative peptide transporter heterodimer. Nature. 1992;355(6361):644-646.

7. Lehner PJ, Cresswell P. Processing and delivery of peptides presented by MHC class I molecules. Curr Opin Immunol. 1996;8(1):59-67.

8. Rosenberg SA, Yang JC, Restifo NP. Cancer immunotherapy: moving beyond current vaccines. Nat Med. 2004;10(9):909-915.

9. Noguchi M, Mine T, Komatsu N, et al. Assessment of immunological biomarkers in patients with advanced cancer treated by personalized peptide vaccination. Cancer Biol Ther. 2011;10(12):1266-1279.

10. Brunsvig PF, Kyte JA, Kersten C, et al. Telomerase peptide vaccination in NSCLC: a phase II trial in stage III patients vaccinated after chemoradiotherapy and an 8-year update on a phase I/II trial. Clin Cancer Res. 2011;17(21):6847-6857.

11. Greenland JR, Letvin NL. Chemical adjuvants for plasmid DNA vaccines. Vaccine. 2007;25(19):3731-3741

12. Dobrovolskaia MA, McNeil SE. Immunological properties of engineered nanomaterials. Nat Nanotechnol. 2007;2(8):469-478.

12. Sahoo SK, Ma W, Labhasetwar V. Efficacy of transferrin-conjugated paclitaxel-loaded nanoparticles in a murine model of prostate cancer. Int J Cancer. 2004;112(2):335-340.

14. Yamamoto H, Kuno Y, Sugimoto S, Takeuchi H, Kawashima Y. Surface-modified PLGA nanosphere with chitosan improved pulmonary delivery of calcitonin by mucoadhesion and opening of the intercellular tight junctions. J Control Release. 2005;102(2):373-381.

15. Zhang N, Chittasupho C, Duangrat C, Siahaan TJ, Berkland C. PLGA nanoparticle-peptide conjugate effectively targets intercellular celladhesion molecule-1. Bioconjug Chem. 2008;19(1):145-152.

16. Campolongo MJ, Luo D. Drug delivery: old polymer learns new tracts. Nat Mater. 2009;8(6):447-448.

17. Prabha S, Labhasetwar V. Nanoparticle-mediated wild-type p53 gene delivery results in sustained antiproliferative activity in breast cancer cells. Mol Pharm. 2004;1(3):211-219.

18. Prabha S, Zhou WZ, Panyam J, Labhasetwar V. Size-dependency of nanoparticle-mediated gene transfection: studies with fractionated nanoparticles. Int J Pharm. 2002;244(1-2):105-115.

19. Panyam J, Zhou WZ, Prabha S, Sahoo SK, Labhasetwar V. Rapid endo-lysosomal escape of poly(DL-lactide-co-glycolide) nanoparticles: implications for drug and gene delivery. FASEB J. 2002;16(10): 1217-1226.
20. Vasir JK, Labhasetwar V. Targeted drug delivery in cancer therapy. Technol Cancer Res Treat. 2005;4(4):363-374.

21. Ma W, Smith T, Bogin V, et al. Enhanced presentation of MHC class Ia, Ib and class II-restricted peptides encapsulated in biodegradable nanoparticles: a promising strategy for tumor immunotherapy. J Transl Med. 2011;9:34.

22. Minev B, Hipp J, Firat H, Schmidt JD, Langlade-Demoyen P, Zanetti M. Cytotoxic $\mathrm{T}$ cell immunity against telomerase reverse transcriptase in humans. Proc Natl Acad Sci U S A. 2000;97(9):4796-4801.

23. de Vries IJ, Lesterhuis WJ, Barentsz JO, et al. Magnetic resonance tracking of dendritic cells in melanoma patients for monitoring of cellular therapy. Nat Biotechnol. 2005;23(11):1407-1413.

24. Mailliard RB, Egawa S, Cai Q, et al. Complementary dendritic cellactivating function of CD8+ and CD4+ T cells: helper role of CD8+ $\mathrm{T}$ cells in the development of T helper type 1 responses. $J$ Exp Med. 2002;195(4):473-483.

25. Craiu A, Akopian T, Goldberg A, Rock KL. Two distinct proteolytic processes in the generation of a major histocompatibility complex class I-presented peptide. Proc Natl Acad Sci US A. 1997;94(20):10850-10855.

26. Garcia-Hernandez Mde L, Gray A, Hubby B, Kast WM. In vivo effects of vaccination with six-transmembrane epithelial antigen of the prostate: a candidate antigen for treating prostate cancer. Cancer Res. 2007;67(3):1344-1351.

27. Ma W, Yu H, Wang Q, Jin H, Solheim J, Labhasetwar V. A novel approach for cancer immunotherapy: tumor cells with anchored superantigen SEA generate effective antitumor immunity. J Clin Immunol. 2004;24(3):294-301.

28. Yang D, Holt GE, Velders MP, Kwon ED, Kast WM. Murine sixtransmembrane epithelial antigen of the prostate, prostate stem cell antigen, and prostate-specific membrane antigen: prostate-specific cell-surface antigens highly expressed in prostate cancer of transgenic adenocarcinoma mouse prostate mice. Cancer Res. 2001;61(15): $5857-5860$.

29. Ito F, Fujimori H, Makino K. Factors affecting the loading efficiency of water-soluble drugs in PLGA microspheres. Colloids Surf B Biointerfaces. 2008;61(1):25-29.

30. Rosenberg SA, Kawakami Y, Robbins PF, Wang R. Identification of the genes encoding cancer antigens: implications for cancer immunotherapy. Adv Cancer Res. 1996;70:145-177.

31. Rew SB, Peggs K, Sanjuan I, et al. Generation of potent antitumor CTL from patients with multiple myeloma directed against HM1.24. Clin Cancer Res. 2005;11(9):3377-3384.

32. Xiang SD, Scalzo-Inguanti K, Minigo G, Park A, Hardy CL, Plebanski M. Promising particle-based vaccines in cancer therapy. Expert Rev Vaccines. 2008;7(7):1103-1119.

33. Mandelboim O, Vadai E, Fridkin M, et al. Regression of established murine carcinoma metastases following vaccination with tumourassociated antigen peptides. Nat Med. 1995;1(11):1179-1183.

34. Mesa C, Fernandez LE. Challenges facing adjuvants for cancer immunotherapy. Immunol Cell Biol. 2004;82(6):644-650.

35. Singh M, O’Hagan D. Advances in vaccine adjuvants. Nat Biotechnol. 1999;17(11):1075-1081.

36. Fifis T, Gamvrellis A, Crimeen-Irwin B, et al. Size-dependent immunogenicity: therapeutic and protective properties of nano-vaccines against tumors. J Immunol. 2004;173(5):3148-3154.

37. Yadav KS, Chuttani K, Mishra AK, Sawant KK. Effect of Size on the Biodistribution and Blood Clearance of Etoposide-Loaded PLGA Nanoparticles. PDA J Pharm Sci Technol. 2011;65(2):131-139.

38. Li SD, Huang L. Nanoparticles evading the reticuloendothelial system: role of the supported bilayer. Biochim Biophys Acta. 2009;1788(10): 2259-2266.

39. Alexis F, Pridgen E, Molnar LK, Farokhzad OC. Factors affecting the clearance and biodistribution of polymeric nanoparticles. Mol Pharm. 2008;5(4):505-515.

40. Acharya S, Sahoo SK. PLGA nanoparticles containing various anticancer agents and tumour delivery by EPR effect. Adv Drug Deliv Rev. 2011;63(3):170-183. 
41. Tsai YM, Chien CF, Lin LC, Tsai TH. Curcumin and its nano-formulation: the kinetics of tissue distribution and blood-brain barrier penetration. Int J Pharm. 2011;416(1):331-338.

42. Gu F, Zhang L, Teply BA, et al. Precise engineering of targeted nanoparticles by using self-assembled biointegrated block copolymers. Proc Natl Acad Sci U S A. 2008;105(7):2586-2591.

43. Dhar S, Gu FX, Langer R, Farokhzad OC, Lippard SJ. Targeted delivery of cisplatin to prostate cancer cells by aptamer functionalized Pt(IV) prodrug-PLGA-PEG nanoparticles. Proc Natl Acad Sci U S A. 2008;105(45):17356-17361.

44. Benny O, Menon LG, Ariel G, et al. Local delivery of poly lactic-co-glycolic acid microspheres containing imatinib mesylate inhibits intracranial xenograft glioma growth. Clin Cancer Res. 2009;15(4):1222-1231.

45. Kaiser-Schulz G, Heit A, Quintanilla-Martinez L, et al. Polylactidecoglycolide microspheres co-encapsulating recombinant tandem prion protein with $\mathrm{CpG}$-oligonucleotide break self-tolerance to prion protein in wild-type mice and induce CD4 and CD8 T cell responses. J Immunol. 2007;179(5):2797-2807

46. Wang X, Wenk E, Hu X, et al. Silk coatings on PLGA and alginate microspheres for protein delivery. Biomaterials. 2007;28(28): 4161-4169.

47. Tse MT, Blatchford C, Oya Alpar H. Evaluation of different buffers on plasmid DNA encapsulation into PLGA microparticles. Int J Pharm. 2009;370(1-2):33-40.

48. Pearton M, Allender C, Brain K, et al. Gene delivery to the epidermal cells of human skin explants using microfabricated microneedles and hydrogel formulations. Pharm Res. 2008;25(2):407-416.

49. Jessel N, Oulad-Abdelghani M, Meyer F, et al. Multiple and timescheduled in situ DNA delivery mediated by beta-cyclodextrin embedded in a polyelectrolyte multilayer. Proc Natl Acad Sci US A. 2006;103(23):8618-8621.
50. Choleris E, Little SR, Mong JA, Puram SV, Langer R, Pfaff DW. Microparticle-based delivery of oxytocin receptor antisense DNA in the medial amygdala blocks social recognition in female mice. Proc Natl Acad Sci U S A. 2007;104(11):4670-4675.

51. Sirsi SR, Schray RC, Wheatley MA, Lutz GJ. Formulation of polylactide-co-glycolic acid nanospheres for encapsulation and sustained release of poly(ethylene imine)-poly(ethylene glycol) copolymers complexed to oligonucleotides. J Nanobiotechnology. 2009;7(1):1.

52. Goforth R, Salem AK, Zhu X, et al. Immune stimulatory antigen loaded particles combined with depletion of regulatory T-cells induce potent tumor specific immunity in a mouse model of melanoma. Cancer Immunol Immunother. 2009;58(4):517-530.

53. Elamanchili P, Diwan M, Cao M, Samuel J. Characterization of poly(D,L-lactic-co-glycolic acid) based nanoparticulate system for enhanced delivery of antigens to dendritic cells. Vaccine. 2004;22(19):2406-2412.

54. Lutsiak ME, Kwon GS, Samuel J. Biodegradable nanoparticle delivery of a Th2-biased peptide for induction of Th1 immune responses. J Pharm Pharmacol. 2006;58(6):739-747.

55. Hamdy S, Molavi O, Ma Z, et al. Co-delivery of cancer-associated antigen and Toll-like receptor 4 ligand in PLGA nanoparticles induces potent CD8+ T cell-mediated anti-tumor immunity. Vaccine. 2008;26(39):5046-5057.

56. Newman KD, Samuel J, Kwon G. Ovalbumin peptide encapsulated in poly(d,1 lactic-co-glycolic acid) microspheres is capable of inducing a $\mathrm{T}$ helper type 1 immune response. J Control Release. 1998;54(1):49-59.

57. Diwan M, Elamanchili P, Lane H, Gainer A, Samuel J. Biodegradable nanoparticle mediated antigen delivery to human cord blood derived dendritic cells for induction of primary T cell responses. J Drug Target. 2003;11(8-10):495-507.
International Journal of Nanomedicine

\section{Publish your work in this journal}

The International Journal of Nanomedicine is an international, peerreviewed journal focusing on the application of nanotechnology in diagnostics, therapeutics, and drug delivery systems throughout the biomedical field. This journal is indexed on PubMed Central,

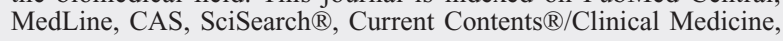

\section{Dovepress}

Journal Citation Reports/Science Edition, EMBase, Scopus and the Elsevier Bibliographic databases. The manuscript management system is completely online and includes a very quick and fair peer-review system, which is all easy to use. Visit http://www.dovepress.com/ testimonials.php to read real quotes from published authors. 